\title{
Teores de As, $\mathrm{Cd}, \mathrm{Pb}, \mathrm{Cr}$ e Ni e atributos de fertilidade de Argissolo Amarelo distrófico usado como lixão no município de Cáceres, estado de Mato Grosso
}

\author{
Arleme Janissara de Oliveira Alcântara ${ }^{1}$, Maria Aparecida Pereira Pierangeli², \\ Célia Alves de Souza ${ }^{3} \&$ Juberto Babilônia de Souza ${ }^{4}$
}

\begin{abstract}
Resumo A disposição inadequada de resíduos sólidos urbanos (RSU) pode comprometer o solo e as águas subterrâneas em decorrência da presença de diversas substâncias contaminantes, dentre elas os metais pesados. Esse estudo objetivou analisar alguns atributos e os teores de alguns metais potencialmente poluidores no solo da área do lixão de Cáceres-MT. Para isso, essa área foi dividida em 3 subáreas: natural, ativa e inativa. Em cada área foram coletadas amostras de solo nas profundidades de 0-0,20 e 0,20-0,40 $\mathrm{m}$, as quais foram submetidas a análises de rotina para avaliação da fertilidade do solo: $\mathrm{pH}$ em água, matéria orgânica (MO), fósforo, potássio, cálcio, magnésio, alumínio, acidez potencial e calculados a capacidade de troca de cátions (CTC a pH 7,0) e efetiva $\left(\mathrm{CTC}_{\text {efe }}\right)$, saturação por bases $(\mathrm{V} \%)$ e saturação por alumínio (m \%); textura; e teores dos metais $\mathrm{As}, \mathrm{Cd}, \mathrm{Pb}, \mathrm{Cr}$ e Ni. Os teores totais de metais pesados foram determinados por espectrometria de emissão óptica, com plasma acoplado indutivamente após extração mediante o método SW 3050B. Não houve diferença significativa entre os valores médios de $\mathrm{pH}$, entre as áreas, ficando os mesmos entre 5,3 e 5,7. Maiores teores de matéria orgânica e $\mathrm{CTC}_{\text {efe }}$ foram verificados na área natural. Os teores de metais pesados presentes no solo do lixão de Cáceres estão abaixo dos valores de referência estabelecidos na literatura. Os baixos teores de argila encontrados do solo da área do lixão não a torna adequada para a disposição de RSU.
\end{abstract}

Palavras-chave: Resíduos sólidos urbanos, Pantanal Matogrossense, contaminação do solo, metais pesados, elementos-traço.

\begin{abstract}
Total contents of As, Cd, Pb, Cr and Ni and soil fertility atributtes in Yellow Argissol used for sanitary landfill in Cáceres city, Mato Grosso state. The inadequate disposal of urban solid wastes (USW) can damage soil and groundwater because it contains contaminant substances, including heavy metals. The aim of this study was to verify chemical attributes and the content of some potentially polluting metals in the soil of the sanitary landfill of Cáceres, in the state of Mato Grosso, Brazil. For this, the area was divided in 03 subareas: natural, active and inactive. Soil samples were collected in these subareas at the depth of $0-0.20$ and $0.20-0.40 \mathrm{~m}$. Such samples were routinely analysed for the purpose of evaluating the soil fertility: water's $\mathrm{pH}$, organic matter, phosphorus, potassium, calcium, magnesium, aluminum, $(\mathrm{m} \%)$, potential acidity, cation exchange capacity (CEC), bases saturation ( $\mathrm{V} \%$ ) and aluminum saturation; texture; and the contents of metals such as $\mathrm{As}, \mathrm{Cd}, \mathrm{Pb}, \mathrm{Cr}$ e Ni. The total contents of heavy metals were determined by spectrometry of optic emission with plasma inductivity after extraction, using method SW 3050B. There wasn't a relevant difference between the average values of $\mathrm{pH}$ among in the areas. The organic matter and CEC reached higher values in the natural area. The heavy metal contents were below the limit baselines established in the literature. The low clay found in the soil of this area does not make it suitable for the disposal of USW.
\end{abstract}

Keywords: urban solid wastes, Pantanal Matogrossense, soil contamination, heavy metals, trace elements.

INTRODUÇÃO Um dos maiores problemas enfrentados pelas cidades é o gerenciamento dos resíduos sólidos produzidos, principalmente, no que tange à sua destinação. Condições inadequadas de descarte desses resíduos podem provocar inúmeros danos ao ambiente. Os resíduos sólidos são considerados a expressão mais visível e concreta dos riscos ambientais, ocupando um papel importante na estrutura de saneamento das comunidades urbanas e, consequentemente, nos aspectos relacionados à saúde publica. Além das consequências para a saúde coletiva, deve-se considerar ainda o impacto que a disposição inadequada desses resíduos provoca no solo, na atmosfera, na vegetação e nos recursos hídricos (Munõz 2002).

Dados do IBGE (2002) destacam que no Brasil 59\% dos municípios destinam seus Resíduos Sólidos Urbanos (RSU) em lixões; 13\% em aterros sanitários; $17 \%$ em aterros controlados; $0,6 \%$ áreas alagadas; $0,3 \%$ em aterros especiais; e apenas $2,8 \%$ têm programas de reciclagem. No estado de Mato Grosso a situação é

1 - Prefeitura Municipal de Cáceres, Secretaria Municipal de Saúde, Cáceres (MT). E-mail: arlenealcantara@hotmail.com 2 - Departamento de Zootecnia, Universidade do Estado de Mato Grosso, Pontes e Lacerda (MT), Brasil. E-mail: mapp@unemat.br

3 - Departamento de Geografia, Universidade do Estado de Mato Grosso, Cáceres (MT), Brasil. E-mail: revistadegeografia@unemat.br

4 - Instituto Federal de Educação, Ciência e Tecnologia de Mato Grosso, Cáceres (MT), Brasil. E-mail: jubertobabilonia@yahoo.com.br 
preocupante em relação à destinação dos RSU, pois dos 141 municípios, apenas $28(20 \%)$ efetivamente estão tomando providências técnicas para destinação adequada dos seus resíduos.

Por ser a maneira mais fácil e barata de disposição de rejeitos, o solo recebe grandes quantidades desses, muitos contaminados com substâncias químicas, potencialmente tóxicas, carcinogênicas ou mutagênicas, como é o caso de produtos da reciclagem de efluentes e lodos industriais ou mesmo resíduos sólidos urbanos (Accioly \& Siqueira 2000). Conforme relatam Celere et al. (2007), as áreas de despejo e de disposição dos resíduos sólidos (lixões, aterros controlados e aterros sanitários) não podem ser consideradas como o ponto final para muitas das substâncias contidas nos resíduos ali dispostos ou produzidas pelo lixo urbano, pois, quando a água, principalmente das chuvas, percola através desses resíduos, várias substâncias orgânicas e inorgânicas são carreadas pelo chorume, líquido escuro que contém altas concentrações de compostos orgânicos e inorgânicos.

Os poluentes inorgânicos tóxicos que ocorrem em solos estão sob a designação de "metais pesados", termo usado para caracterizar um grande grupo de elementos com densidade atômica elevada (maior que $5,0 \mathrm{~g} \mathrm{~cm}^{-}$ ${ }^{3}$ ) ou massa atômica maior que 20 . Os metais pesados englobam alguns elementos considerados elementos tóxicos ou não essenciais, como o $\mathrm{Pb}, \mathrm{Cd}, \mathrm{Hg}, \mathrm{As}, \mathrm{Ti}$, e $\mathrm{U}$, bem como elementos essenciais ou micronutrientes, que são aqueles requeridos pela maioria dos seres vivos em pequenas concentrações, mas que podem se tornar tóxicos em elevadas concentrações, como é o caso de $\mathrm{Cu}, \mathrm{Mn}, \mathrm{Fe}$ e $\mathrm{Zn}$ às plantas e animais, $\mathrm{Co}, \mathrm{Cr}$, Se e I para os animais e $\mathrm{B}, \mathrm{Mo}$, e Ni exclusivamente para as plantas (Guilherme et al. 2005). Porém, esses autores destacam que o termo "metal "pesado" é erroneamente utilizado na literatura que trata desse tema, pois conforme Duffus (2001) a International Union Of Pure and Applied Chemistry (IUPAC) considera que o termo "metal" se refere ao elemento puro, que possui propriedades físicas e químicas bem características, e não dos seus compostos, cujas propriedades físicas, químicas, biológicas e toxicológicas são muitas vezes diferentes. Além disso, a IUPAC recomenda a proibição do termo, pois se trata de uma nova classificação de elementos na tabela periódica, agrupando metais e metaloides sem bases científicas definidas (Duffus 2001). Sendo assim, doravante nesse trabalho será adotado o termo elementos traço para se referir aos elementos com potencial de contaminação e toxicidade para o ambiente. Conforme Mucelin \& Bellini (2008), os elementos-traço em solos são derivados tanto do intemperismo da rocha de origem, como de fontes externas naturais (erupção vulcânica) ou antrópicas (indústrias, agricultura, disposição de resíduos).

Elementos tóxicos como chumbo, mercúrio, cádmio, arsênio, cromo, zinco e manganês, dentre outros, estão presentes em diversos tipos de resíduos levados para lixões, podendo ser encontrados em: lâmpadas, pilhas, baterias, tintas, produtos de limpeza, óleos lubrificantes, solventes, aerossóis, amálgama, materiais fotográficos e radiográficos, embalagens de produtos químicos, pesticidas, fungicidas e inseticidas, componentes eletrônicos, produtos farmacêuticos, latarias de alimentos, aditivos alimentares e plásticos descartados (Munõz 2002).

A contaminação do ambiente por elementos traço em virtude de descargas de efluentes urbanos e industriais tem sido relatada na literatura (Rosolen et al. 2009). O solo atua frequentemente como um "filtro", tendo a capacidade de depuração e imobilizando grande parte das impurezas nele depositadas (Casarini \& Lemos 2001, Guilherme et al. 2005). No entanto, essa capacidade é limitada, podendo ocorrer alteração da qualidade do solo, devido ao efeito cumulativo da deposição de poluentes atmosféricos, a aplicação de defensivos agrícolas e fertilizantes e à disposição de resíduos sólidos industriais, urbanos, materiais tóxicos e radioativos.

Os elementos-traço que são incorporados nos solos podem seguir diferentes vias de retenção ou transporte. Podem ficar retidos no solo, dissolvidos na solução do solo ou fixados por processos de adsorção, complexação e precipitação (Kabata-Pendias \& Pendias 2001). Também podem ser absorvidos pelas plantas e, assim, ser incorporados na cadeia trófica ou podem passar para o ar por volatização ou mover-se para águas superficiais ou subterrâneas (Accioly \& Siqueira 2000).

A concentração média de cádmio na crosta terrestre é de $0,15 \mathrm{mg} \mathrm{kg}^{-1}$, sendo pouco móvel no perfil do solo (Kabata Pendias \& Pendias 2001). Para o estado de São Paulo, a CETESB toma como valor de referência para solos não contaminados o teor de $0,5 \mathrm{mg} \mathrm{kg}^{-1}$ (CETESB 2005). No estado de Mato Grosso, teores médios de $0,45 \mathrm{mg} \mathrm{kg}^{-1}( \pm 0,26)$ em solos de vegetação nativa são relatados por Pierangeli et al. (2009).

Com densidade de $11,34 \mathrm{~g} \mathrm{~cm}^{-3}$, o chumbo é utilizado na fabricação de baterias, sendo usado também na gasolina, em pigmentos, munição e soldas. Ocorre como contaminante ambiental e as concentrações no meio ambiente cresceram de acordo com o aumento do seu uso industrial (Mavropoulos 1999). O teor de chumbo nos solos varia de região a região: em regiões próximas às vias de tráfego intenso e de indústrias, os teores de chumbo são bem mais elevados que aqueles encontrados em áreas isoladas (Lauerman 2007). Em Latossolos brasileiros são relatados teores médios de $\mathrm{Pb}$ em torno de $17 \mathrm{mg} \mathrm{kg}^{-1}$ (Pierangeli et al. 2001), porém, teores tão altos quanto $9.678 \mathrm{mg} \mathrm{kg}^{-1}$ de chumbo em solos são relatados em áreas próximas à área de metalurgia $\mathrm{e}$ mineração de $\mathrm{Pb}$ em Adrianóplis - PR (Andrade 2009).

$\mathrm{O}$ cromo $(\mathrm{Cr})$ possui densidade $7,19 \mathrm{~g} \mathrm{~cm}^{-3}$ sendo utilizado na fabricação de ligas metálicas empregadas na indústria de transporte, construções e fabricação de maquinários, fabricação de tijolos refratários, indústria têxtil, fotográfica e de vidros (Chagas 2000). Os níveis de $\mathrm{Cr}$ na água, geralmente, são baixos $(9,7 \mu \mathrm{g}$ $\mathrm{L}^{-1}$ ), embora níveis maiores já tenham sido relatados como consequência do lançamento nos rios de RSU contendo este metal (Damasceno 1996 apud Oliveira 2001). A atividade biológica do cromo, isto é, seu efeito 
como metal essencial à vida, está restrito à sua forma trivalente, que se mostra necessário para a prevenção da diabete e arteriosclerose. Para Chagas (2000), o cromo hexavalente $\left(\mathrm{Cr}^{6+}\right)$, este sim, é corrosivo à mucosa em teores de $10 \mathrm{mg} \mathrm{kg}^{-1}$ de peso corporal, podendo ser absorvido por ingestão, através da pele ou inalação, provocando câncer de pulmão, perfuração do septo nasal e outras complicações respiratórias. Embora, esta forma de cromo possa ser encontrada na maioria dos sistemas biológicos, ainda são desconhecidos seus efeitos benéficos ao ser humano. O Cr é um elemento muito distribuído nos solos, águas e materiais biológicos. $\mathrm{O}$ teor médio de Cr nos solos varia de 100 e $300 \mathrm{mg} \mathrm{kg}^{-1}$. De modo geral, apenas uma fração muito pequena de cromo total do solo é disponível para as plantas (Chagas 2000). Segundo a CETESB (2005), os valores de referência para solos não contaminados, no estado de São Paulo, são teores abaixo de $40 \mathrm{mg} \mathrm{kg}^{-1}$.

$\mathrm{O}$ elemento níquel (Ni), com densidade $8,90 \mathrm{~g}$ $\mathrm{cm}^{-3}$, é utilizado na produção de ligas, na indústria de galvanoplastia, na fabricação de baterias juntamente com o cádmio (baterias Ni-Cd), em componentes eletrônicos, produtos de petróleo, pigmentos e como catalisadores para hidrogenação de gorduras (Damasceno 1996 apud Oliveira 2001). O teor de Ni no solo é muito variável dependendo de fatores como a rocha de origem. Os valores médios mundiais estão entre 20 e $40 \mathrm{mg} \mathrm{kg}^{-1}$ (Chagas 2000). Segundo a CETESB (2005), teores de $\mathrm{Ni}$ abaixo de $13 \mathrm{mg} \mathrm{kg}^{-1}$ são valores de referência para solos não contaminados, no estado de São Paulo. Problemas de contaminação de águas com níquel estão associados com a descarga de efluentes industriais contendo altos teores desse metal.

Elevadas concentrações de As no solo podem acontecer naturalmente devido ao intemperismo de rochas ricas em arsenopirita. De modo geral, as rochas apresentam teores variados de As. As rochas metamórficas apresentam concentrações que refletem suas precursoras ígneas e sedimentares, com teores inferiores a $5 \mathrm{mg} \mathrm{kg}^{-1}$. As rochas sedimentares têm teores de As superiores à média da crosta terrestre $\left(2 \mathrm{mg} \mathrm{kg}^{-1}\right)$, pois podem funcionar como verdadeiros "filtros" das soluções geradas pelo intemperismo da crosta superficial (Kabata-Pendias \& Pendias 2001). A tendência de concentração de As nas rochas sedimentares depende da proporção de sulfetos, óxidos, matéria orgânica e argilominerais presentes nos sedimentos (Ladeira et al. 2002).

Além da origem pelo intemperismo das rochas, as atividades antropogênicas são fontes de As para o ambiente. Provêm basicamente do uso continuado de seus compostos como pesticidas, preservativos da madeira, da sua emissão durante a mineração e fundição de ouro, chumbo, cobre e níquel, da produção de ferro e aço e da combustão de carvão, do qual é um contaminante (Sakuma et al. 2003). Nos solos, o tempo de retenção do As é em função de características do solo, tais como $\mathrm{pH}$, teores de matéria orgânica e de óxidos de Al e Fe (Kabata-Pendias \& Pendias 2001). Além disso, as condições hidrológicas e climáticas também interferem de maneira significativa nas interações do
As com o solo. De forma geral, os teores de arsênio nos solos variam de 0,21 a $41 \mathrm{mg} \mathrm{kg}^{-1}$, mas em solos agrícolas contaminados esse valor pode chegar a 600 $\mathrm{mg} \mathrm{kg}^{-1}$ (Kabata-Pendias \& Pendias 2001). Os teores de referência de qualidade para o As em solos de São Paulo é de 3,5 $\mathrm{mg} \mathrm{kg}^{-1}$ de solo (CETESB 2005). No estado de Mato Grosso, Pierangeli et al. (2009) relataram teores médios de As iguais a 43,9 $\mathrm{mg} \mathrm{kg}^{-1}$ em área de vegetação nativa e $101,13 \mathrm{mg} \mathrm{kg}^{-1} \mathrm{em}$ área de garimpo.

A Companhia Ambiental do estado de São Paulo (CETESB 2005) é o órgão que dispõe sobre os valores orientadores de elementos traço para solos e águas subterrâneas no estado de São Paulo. Entre esses valores está o Valor de Referência de Qualidade (VRQ), o qual se refere à concentração nativa de determinada substância ou elemento no solo ou na água subterrânea. Esse valor deve ser utilizado como referência de qualidade nas ações de prevenção da poluição do solo e das águas subterrâneas e de controle de áreas contaminadas. Estudos para determinação dos valores nativos de elementos traços poluentes em solos têm sido realizados em diversos estados do Brasil, conforme relatos de Paye et al. (2010), porém, no estado de Mato Grosso isso ainda não foi realizado.

Atributos dos solos como $\mathrm{pH}$, textura e composição mineral (teor e tipos de argilas, teor de óxidos de ferro, alumínio e manganês), teor de matéria orgânica, capacidade de troca de cátions (CTC), potencial de oxirredução, composição da solução do solo e a temperatura do ambiente (Guilherme et al. 2005), bem como das propriedades de cada metal influenciam na capacidade de retenção, que são dependentes de reações químicas e de processos microbiológicos. Solos de textura argilosa, por exemplo, apresentam uma maior capacidade de reter os metais provenientes da decomposição do lixo ou de outra fonte qualquer. Isso, porque esses solos apresentam em geral maior CTC, disponibilizando cargas negativas onde os metais pesados podem se ligar. Essa ligação geralmente acontece por complexo de esfera interna, ou seja, é uma ligação muito forte, capaz de imobilizar o metal, diminuindo muito os riscos de lixiviação desses elementos, o que, a princípio, evitaria a contaminação do lençol freático e a contaminação dos solos próximos ao local (Zanchetta 2007). Fadigas et al. (2002) estudaram teores de metais em alguns solos brasileiros, verificando que os teores de argila mostraram correlação positiva e significativa com os teores de Fe, Cd, Zn, Ni e Cr. Trabalhos de Pierangeli et al. (2003), enfatizaram a importância de vários atributos do solo $(\mathrm{pH}$, matéria orgânica, força iônica, teores de argila etc.) na retenção de $\mathrm{Pb}$ e $\mathrm{Cd}$.

Assim, o solo pode servir como meio atenuante de contaminantes através de processos físicos, químicos e biológicos de interação solo-poluente. Segundo Santos (1996), acreditava-se que, no passado, os percolados do lixo eram completamente purificados pelo solo e, desta forma, não havia a preocupação com relação à contaminação das águas subterrâneas. Todavia, sabe-se atualmente que essa capacidade de atenuação do solo foi superestimada, admitindo a necessidade de 
maior atenção para minimizar prejuízos advindos dessa atividade (Castilhos Jr. 2003). Em geral, os solos com alto teor de argila apresentam baixa permeabilidade, e por isso são frequentemente utilizados como barreiras naturais e artificiais em sítios de disposição de resíduos para limitar o escape dos contaminantes, tanto para o lençol freático quanto para o solo (Zanchetta 2007).

Para salvaguardar a saúde e qualidade de vida dos seres humanos e dos ecossistemas, os órgãos de controle ambiental necessitam de indicadores de contaminação ambiental do solo pelas atividades antrópicas. Guilherme et al. (2005) reforçam que a minimização dos impactos causados pela poluição do solo e da água é fundamental para a melhoria da qualidade ambiental e para o desenvolvimento sustentável, visando a redução de possíveis efeitos deletérios sobre a saúde humana e ambiental. Diante disso, o estudo dos teores de metais pesados na área de deposição de lixo em Cáceres-MT é apenas uma das variáveis desse importante problema de saneamento que envolve questões de natureza social, ambiental, sanitária, política e econômica.

O objetivo desse estudo foi avaliar os teores elementos traço $\mathrm{As}, \mathrm{Cd}, \mathrm{Pb}, \mathrm{Cr}, \mathrm{Hg}$ e $\mathrm{Ni}$ e atributos da fertilidade do solo na área destinada ao recebimento dos RSU (Lixão Municipal) da cidade de Cáceres-MT.

Contexto Geológico A área do Lixão de Cáceres está localizada na Bacia do córrego Piraputangas, na cabeceira do Pantanal mato-grossense, nas margens da BR MT-343. É uma propriedade particular de aproximadamente 30 ha, arrendada à Prefeitura Municipal de
Cáceres, utilizada há cerca de dez anos para a disposição de resíduos sólidos provenientes da coleta pública, o qual perfaz cerca de 40 toneladas diariamente (Alcântara \& Pierangeli 2010) (Fig. 1).

Essa bacia hidrográfica (coordenadas $15^{\circ} 57^{\prime}$ a $16^{\circ} 12^{\prime}$ de latitude sul e $57^{\circ} 30^{\prime}$ a $57^{\circ} 42^{\prime}$ de longitude oeste) da área do Lixão cujo rio principal é o córrego das Piraputangas, apresenta uma área de $170 \mathrm{~km}^{2}$. A área está sobre a formação geológica Raizama e os solos predominantes são Argissolos Vermelho Amarelo distrófico (Souza 1998).

A bacia hidrográfica do córrego das Piraputangas apresenta dois períodos bem definidos em termos de precipitação: época de chuvas intensas (outubro a março) com média de precipitação mensal que varia de 100 a $370 \mathrm{~mm}$ e período de estiagens (abril a setembro), com média de precipitação mensal que varia de 10 a 80 $\mathrm{mm}$, com diferença de vazões acentuadas entre os dois períodos (Souza et al. 2010).

De acordo com estudos realizados por Luz (1978), a área em estudo apresenta diferentes formações geológicas datadas do Pré-Cambriano Superior ao Cenozoico (Grupo Alto Paraguai: Formação Araras, Formação Raizama e Formação Sepotuba), ao Quaternário (aluviões atuais e antigos). Os estudos efetuados pelo projeto RADAMBRASIL (1982) mostram que a litologia da bacia constitui-se de arenitos, siltitos e argilitos, sedimentos não consolidados (aluviões atuais e antigos), sedimentos finos a grosseiros semiconsolidados (Formação Pantanal), calcários calcíticos e dolomíticos calcíticos (Formação Araras), arenitos finos a médios

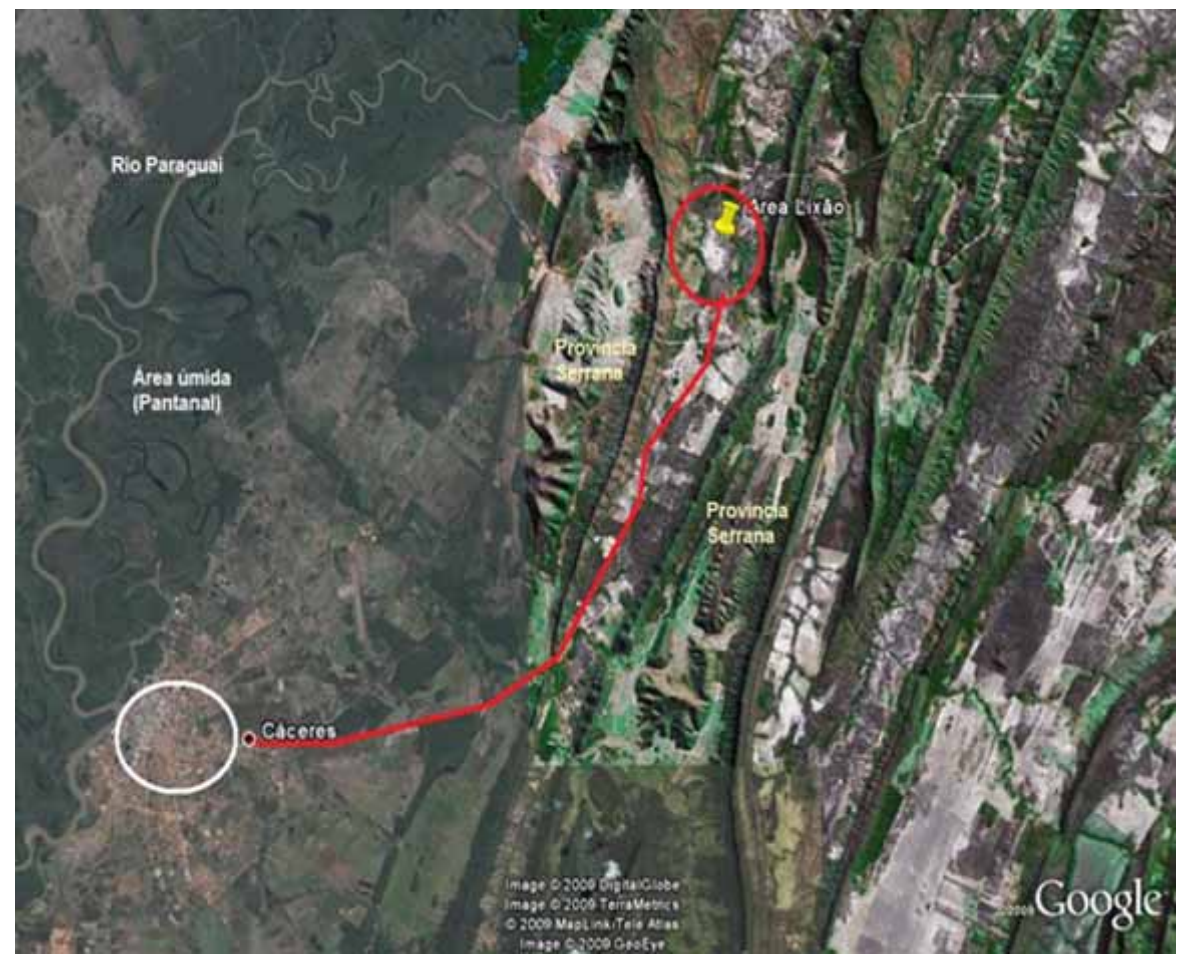

Figura 1 -Imagem de área do município de Cáceres, destacando a localização do Lixão. Adaptado de Google Earth (2011). 
com frequentes camadas de conglomerados (Formação Raizama) e folhelhos e siltitos (Formação Sepotuba).

A bacia hidrográfica apresenta variações marcantes nos aspectos geomorfológicos, como a Província Serrana (Superfície Dissecada), a depressão de rebaixamento (depressão do alto Paraguai) e a superfície de acumulação caracterizada como planície de inundação (sedimentar). Os estudos realizados por Ross (1987) contribuíram para classificar o relevo da Província Serrana (Superfície Dissecada) como um conjunto de anticlinais e sinclinais formando um alinhamento de serras grosseiramente paralelas entre si, com plano de concavidade voltado para o sudoeste, caracterizado por forte presença de dobras e secundariamente falhas, onde o processo erosivo atuou em diferentes fases ao longo do Cenozoico, e até mesmo no Mesozoico. O relevo atual é resultado das fases erosivas que atuaram na estrutura dobrada, de diferentes formações litológicas. Apresenta-se com variadas formas, ocorrendo estrutura em anticlinais com dorsos preservados, erodidos, vales de sinclinais preservados, sinclinais alçados, escarpas estruturais geradas por falhas, depressões embutidas e arrasadas por erosão. Pode-se destacar a relação entre cristas ou relevo alto (presença de rochas areníticas), os relevos baixos dos vales sinclinais (presença dos siltitos e folhelhos) e a ocorrência dos calcários no interior dos anticlinais erodidos ou na parte externa das bordas sinclinais alçadas, podendo-se observar uma associação do relevo invertido e formas concordantes com a disposição estrutural.

A Depressão do Alto Paraguai corresponde a uma superfície de relevo pouco dissecada, com pequeno caimento topográfico de nordeste para sudoeste, interflúvios razoavelmente amplos, com topos planos e drenagem pouco profunda. O nível altimétrico oscila entre 120 e $160 \mathrm{~m}$. Conforme o mapeamento geomorfológico do Projeto RADAMBRASIL (1982), os sedimentos da Depressão do Alto Paraguai foram classificados como pertencentes à Formação Pantanal e definidas três idades para os mesmos: aluviões antigos, aluviões sub-recentes e aluviões recentes, apresentando fraca dissecação no relevo.

A forma de acumulação de sedimentos mais recentes é representada pela planície sedimentar, no baixo curso da bacia, próximo à confluência com o rio Paraguai. Neste trecho verificam-se inundações periódicas e acumulações de sedimentos fluviais marcadas por diques e meandros abandonados. Almeida (1964) reconhece que os depósitos constituintes desta formação são pouco espessos, de natureza arenosa fina, síltico-argiloso com cascalho disperso resultante da atuação dos rios.

Quanto à ocupação da bacia, a construção da rodovia MT-343 contribuiu para facilitar o acesso acelerando o processo substitutivo das matas e cerrados por pastagens. A atividade pecuária expandiu na depressão do alto Paraguai, no médio curso e nos vales do alto curso ocupando um papel de destaque na economia local. No alto curso da bacia hidrográfica surgem pisciculturas e carvoarias, como atividades alternativas, e no médio curso encontram-se instalados o Aeroporto Internacional de Cáceres e dois lixões.

\section{MATERIAIS E MÉTODOS}

Procedimento amostral Oficialmente a área em estudo é considerada um aterro controlado, todavia, devido à tendência de operacionalização acaba por caracterizar-se como lixão, considerando-se que, eventualmente, os resíduos são queimados ou depositados em valas e, na maioria das vezes, ficam expostos a céu aberto. A área de estudo, para critério metodológico e procedimento amostral, foi dividida em três subáreas, considerando o uso e ocupação da mesma: área ativa (AA), local que recebe atualmente resíduos sólidos diariamente (não apresenta nenhuma cobertura vegetal); área inativa $(\mathrm{AI})$, local já utilizado para deposição de lixo, todavia está inativa há aproximadamente cinco anos, sendo coberta por vegetação graminoide; e área natural (AN), área testemunha, adjacente à área do lixão ativo, porém onde nunca foram depositados resíduos sólidos, tendo cobertura vegetal típica do Cerrado, com árvores tortuosas de pequeno porte.

Cada subárea com cerca de $100 \mathrm{~m}^{2}$ foi subdividida em 12 pontos de coleta, onde a distância entre cada ponto variou em torno de $25 \mathrm{~m}$. Dessa maneira, foram constituídas 12 repetições por subáreas nas profundidades 0,0 a 0,2 m e 0,2 a 0,4 m. A distância (borda) entre as subáreas foi de aproximadamente $100 \mathrm{~m}$.

As orientações para coleta de solo seguiu o preconizado em Santos et al. (2005). Para a caracterização dos atributos químicos e físicos do solo foram coletadas amostras nas profundidades de 0-0,2 e 0,2-0,4 $\mathrm{m}$ de profundidade, coletando-se $0,5 \mathrm{~g}$ de solo por ponto de amostragem, que foram armazenados em sacos plásticos. Posteriormente as amostras foram secas ao ar, destorroadas, peneiradas e armazenadas.

Para realização da análise granulométrica, foram utilizadas as amostras, referentes ao traçado de um transecto diagonal em cada área, perfazendo três amostras em cada profundidade (0-0,2 e 0,2-0,4 m), totalizando seis amostras por área.

Análise de As, Cd, Cr, Ni e Pb O método utilizado para extração dos elementos-traço $\mathrm{Cd}, \mathrm{Pb}, \mathrm{Cr}, \mathrm{Ni}$, e $\mathrm{As}$ foi o SW 3050B (Abreu et al. 2002) e a determinação dos mesmos nos extratos foi realizado por espectrometria de emissão óptica com plasma acoplado indutivamente (ICP-AES) no Laboratório Exata, em Jataí-GO.

Informações obtidas junto à Secretaria de Estado de Meio Ambiente - SEMA, órgão estadual responsável pela fiscalização das ações ambientais, no estado de Mato Grosso, indicam que nesse estado ainda não foram estabelecidos os valores orientadores para concentrações de metais em solos de áreas suspeitas de contaminação ambiental. Considerando essas informações, a interpretação dos teores dos metais $\mathrm{As}, \mathrm{Cd}, \mathrm{Cr}$, $\mathrm{Pb}$, e Ni no solo do lixão de Cáceres-MT foi realizada com base nos valores estipulados para solos do estado de São Paulo, descrito em CETESB (2005). 
Análise dos atributos de fertilidade do solo Todas as determinações relativas aos atributos de fertilidade do solo foram realizadas conforme estabelecido em Embrapa (1997). Para a textura utilizou-se o método da pipeta; $\mathrm{pH}$ em água $(1: 2,5)$, carbono orgânico (CO) (oxidação via úmida com $\mathrm{K}_{2} \mathrm{Cr}_{2} \mathrm{O}_{7} 0,4 \mathrm{~mol} \mathrm{~L}^{-1}$ ), sendo a MO obtida multiplicando-se o valor do $\mathrm{CO}$ por 1,724. Fósforo $(\mathrm{P})$ e potássio $(\mathrm{K})$ foram extraídos com a solução Mehlich ${ }^{-1}$ e magnésio $\left(\mathrm{Mg}^{2+}\right)$, cálcio $\left(\mathrm{Ca}^{2+}\right)$ e alumínio $\left(\mathrm{Al}^{3+}\right)$ determinados com KCl $1 \mathrm{~mol} \mathrm{~L}^{-1}$. Parâmetros como capacidade de troca de cátions total $(\mathrm{CTC}$ a $\mathrm{pH}$ $7,0)$ e efetiva $\left(\mathrm{CTC}_{\text {efe }}\right)$, saturação por bases (V) e saturação por alumínio (m) foram calculados para todas as amostras, conforme descrito por Ribeiro et al. (1999).

Além disso, foi realizada a descrição morfológica do solo da área do lixão de Cáceres-MT, conforme estabelecido em Santos et al. (2006), sendo o solo classificado de acordo com critérios da Embrapa (2006).

Análises estatísticas Os resultados foram submetidos a análises estatísticas, utilizando-se o programa $\mathrm{R}$ versão 2.9.0. Efetuou-se o teste de normalidade em todas as variáveis: teores de metais, atributos do solo, áreas e profundidades. Na existência da normalidade, aplicou-se a análise de variância, utilizando o teste de Fischer "F". A análise de algumas variáveis implicou na transformação dos dados mediante a logaritmização dos valores. Foi realizado o teste de Tukey em nível de $5 \%$ para comparação das médias.

RESULTADOS E DISCUSSÃO A descrição morfológica do perfil do solo do lixão mostrou que esse apresenta sequência de horizontes $A-A B-B_{t 1}-B_{t 2}-B C$, os quais se encontram sobre arenitos ortoquartzíticos com intercalações de siltitos e argilitos (Formação Raizama). O perfil apresentou uma estrutura típica de Argissolo (tipo blocos angulares e subangulares e tamanhos pequeno, médio a grande, de grau moderado a forte).

$\mathrm{O}$ horizonte A apresentou espessura de $20 \mathrm{~cm}$, apresentando textura arenosa ( $823 \mathrm{~g} \mathrm{~kg}^{-1}$ de areia; $86 \mathrm{~g}$ $\mathrm{kg}^{-1}$ de silte; e $91 \mathrm{~g} / \mathrm{kg}$ de argila). O horizonte $\mathrm{AB}$ apresentou $25 \mathrm{~cm}$ de espessura (20-45 cm), apresentando a mesma textura arenosa (776 g kg-1 de areia; $116 \mathrm{~g} \mathrm{~kg}^{-1}$ de argila e $108 \mathrm{~g} \mathrm{~kg}^{-1}$ de silte). $\mathrm{O}$ horizonte $\mathrm{B}_{\mathrm{t1}}$, com profundidade de $45-90 \mathrm{~cm}$ possui textura média (654 $\mathrm{g} \mathrm{kg}^{-1}$ de areia; $185 \mathrm{~g} \mathrm{~kg}^{-1}$ de argila; e $161 \mathrm{~g} \mathrm{~kg}^{-1}$ de silte). $O$ horizonte $B_{t 2}$ de $90-120 \mathrm{~cm}$, também apresentou textura média $\left(633 \mathrm{~g} \mathrm{~kg}^{-1}\right.$ de areia; $188 \mathrm{~g} \mathrm{~kg}^{-1}$ de argila; e $149 \mathrm{~g} \mathrm{~kg}^{-1}$ de silte. O horizonte BC, localizado entre 120-150 $(+) \mathrm{cm}$ também apresentou textura média (627 $\mathrm{g} \mathrm{kg} \mathrm{g}^{-1}$ de areia; $218 \mathrm{~g} \mathrm{~kg}^{-1}$ de argila; e $155 \mathrm{~g} \mathrm{~kg}^{-1} \mathrm{de}$ silte). A proporção granulométrica entre os horizontes do solo mostra um gradiente ao longo do perfil, caracterizando um aumento gradual no teor de argila $(\mathrm{A}=$ $91 \mathrm{~g} / \mathrm{kg} ; \mathrm{AB}=116 \mathrm{~g} / \mathrm{kg} ; \mathrm{Bt} 1=185 \mathrm{~g} / \mathrm{kg} ; \mathrm{Bt} 2=188 \mathrm{~g} /$ $\mathrm{kg}$ e $\mathrm{BC}=218 \mathrm{~g} / \mathrm{kg}$ ). O solo da área foi classificado como Argissolo Vermelho-Amarelo distrófico arênico, corroborando com os estudos de Souza (1998).

A análise granulométrica (Tab. 1) do solo das 03 áreas (natural, ativa e inativa) apontou para uma textura arenosa nas duas profundidades analisadas $(0-$ $0,2 \mathrm{~m}$ e $0,2-0,4 \mathrm{~m}$ ), apesar de se observar na camada mais profunda um aumento discreto no teor médio de argila. Também foram observados teores maiores de argila nos solos da área natural, comparativamente às áreas ativa e inativa, conforme tabela 1. Isso provavelmente é devido ao transporte de materiais mais finos em função da remobilização do solo pelas máquinas que enterram os RSU.

Os teores dos elementos traço avaliados nesse estudo são mostrados na tabela 2. Não houve diferença estatística entre os teores em função das diferentes áreas estudadas. $\mathrm{O}$ transporte e a retenção de metais em solos de áreas de disposição de resíduos sólidos urbanos têm sido motivo de estudo de vários autores e o comportamento observado é de significativo potencial de retenção de metais nos solos, em especial nos argilosos (Suzuki et al. 2005, Beck 2005). Korf et al. (2008) apontaram diversos estudos indicando alta capacidade de retenção de metais em solos argilosos. Estudos de Oliveira \& Jucá (2004) observaram a retenção de metais de lixiviados em solos argilosos de aterros sanitários e Lange et al. 2002 apud Korf et al. (2008) confirmaram a retenção de metais, em especial o $\mathrm{Cr}$, em solos com maiores teores de argila.

A natureza arenosa da área representa inadequação da mesma para depósito de lixo, pois a mesma favorece a lixiviação em detrimento da retenção de poluentes (Korf et al. 2008). Baixos teores de argila, como verificados no solo desta área, contribuem para uma menor CTC e, consequentemente, menor adsorção de metais, conforme verificado para $\mathrm{Cd}$ e $\mathrm{Pb}$ (Pierangeli et al. 2001) em Latossolos. Conforme Rocca et al. (1993), solos adequados para disposição de RSU e implantação de aterros devem conter teores de argila em torno de 560 a $620 \mathrm{~g} \mathrm{~kg}^{-1}$. Para teores de argila inferiores a esses deve ser construído um sistema de impermeabilização, o que não ocorre na área em estudo.

Em todas as amostras de solo avaliadas os elementos analisados apresentaram teores inferiores aos limites estabelecidos pela CETESB (2005), como valores de referência para solos não contaminados, os quais são: As $\left(3,5 \mathrm{mg} \mathrm{kg}^{-1}\right), \mathrm{Cd}\left(>0,5 \mathrm{mg} \mathrm{kg}^{-1}\right), \mathrm{Cr}(40 \mathrm{mg}$ $\left.\mathrm{kg}^{-1}\right)$, Ni (13 $\left.\mathrm{mg} \mathrm{kg}^{-1}\right)$ e $\mathrm{Pb}\left(17 \mathrm{mg} \mathrm{kg}^{-1}\right)$. Fadigas et al. (2002) caracterizaram diversos solos brasileiros, em condições naturais, quanto aos teores totais dos metais pesados. Para esse autor, à exceção do $\mathrm{Cd}$, as concentrações médias dos metais estudados foram, em geral, inferiores aos valores de referência estabelecidos para os solos do estado de São Paulo (CETESB 2005), sendo o mesmo verificado por Paye et al. (2010) em solos do estado do Espírito Santo. Estudos de Pierangeli et al. (2009) no sudoeste do estado de Mato Grosso também relatam teores de Cd, As e Hg superiores aos VRQ de solos do estado de São Paulo. Ressalta-se, assim, a necessidade de estabelecimento de valores de referência mais regionalizados uma vez que diferenças nas condições geológicas, climáticas e pedológicas podem resultar em teores de metais diversos. 
Tabela 1 - Valores médios de alguns atributos químicos e granulométricos do solo da Área Natural, Área Ativa e Área Inativa.

\begin{tabular}{lcccccc}
\hline \multirow{2}{*}{ Atributos } & \multicolumn{2}{c}{ Área Natural } & \multicolumn{2}{c}{ Área ativa } & \multicolumn{2}{c}{ Área Inativa } \\
\cline { 2 - 7 } & $0-0,2 \mathrm{~m}$ & $0,2-0,4 \mathrm{~m}$ & $0-0,2 \mathrm{~m}$ & $0,2-0,4 \mathrm{~m}$ & $0-0,2 \mathrm{~m}$ & $0,2-0,4 \mathrm{~m}$ \\
\hline $\mathrm{pH}$ água & 5,52 & 5,31 & 5,59 & 5,22 & 5,42 & 5,72 \\
\hline $\mathrm{MO}\left(\mathrm{g} \mathrm{kg}^{-1}\right)$ & 34,15 & 36,38 & 35,90 & 37,98 & 39,13 & 38,73 \\
\hline $\mathrm{P}\left(\mathrm{cmol}_{\mathrm{c}} \mathrm{dm}^{-3}\right)$ & 1,36 & 1,43 & 1,79 & 0,55 & 1,56 & 2,55 \\
\hline $\mathrm{K}\left(\mathrm{cmol}_{\mathrm{c}} \mathrm{dm}^{-3}\right)$ & 65,52 & 54,93 & 78,13 & 60,65 & 48,47 & 83,02 \\
\hline $\mathrm{Ca}^{2+}\left(\mathrm{cmol}_{\mathrm{c}} \mathrm{dm}^{-3}\right)$ & 0,46 & 0,20 & 0,55 & 0,36 & 0,22 & 0,46 \\
\hline $\mathrm{Mg}^{2+}\left(\mathrm{cmol}_{\mathrm{c}} \mathrm{dm}^{-3}\right)$ & 0,64 & 0,46 & 0,51 & 0,31 & 0,36 & 0,39 \\
\hline $\mathrm{Al}^{3+}\left(\mathrm{cmol}_{\mathrm{c}} \mathrm{dm}^{-3}\right)$ & 0,68 & 1,48 & 0,60 & 1,00 & 1,00 & 0,55 \\
\hline $\mathrm{H}+\mathrm{Al}\left(\mathrm{cmol}_{\mathrm{c}} \mathrm{dm}^{-3}\right)$ & 6,23 & 5,99 & 6,46 & 6,30 & 6,52 & 6,66 \\
\hline $\mathrm{SB}\left(\mathrm{cmol}_{\mathrm{c}} \mathrm{dm}^{-3}\right)$ & 1,27 & 0,81 & 1,26 & 0,82 & 0,70 & 1,06 \\
\hline $\mathrm{CTC}$ & $\left(\mathrm{cmol}_{\mathrm{c}} \mathrm{dm}^{-3}\right)$ & 2,29 & 1,86 & 1,82 & 1,70 & 1,61 \\
\hline $\mathrm{CTC}$ & $\left(\mathrm{cmol}_{\mathrm{c}} \mathrm{dm}^{-3}\right)$ & 6,80 & 7,72 & 7,12 & 7,22 & 7,72 \\
\hline $\mathrm{V}(\%)$ & 7,50 & 11,78 & 15,43 & 11,29 & 9,61 & 13,27 \\
\hline $\mathrm{m}(\%)$ & 16,63 & 65,08 & 36,02 & 52,95 & 59,10 & 35 \\
\hline Argila $\left(\mathrm{g} \mathrm{kg}^{-1}\right)$ & 35,77 & 117 & 87 & 99 & & 84 \\
\hline Silte $\left(\mathrm{g} \mathrm{kg}^{-1}\right)$ & 101 & 131 & 124 & 130 & 119 & 92 \\
\hline Areia $\left(\mathrm{g} \mathrm{kg}^{-1}\right)$ & 132 & 752 & 789 & 771 & 797 & 115 \\
\hline
\end{tabular}

${ }^{1} \mathrm{MO}=$ matéria orgânica; $\mathrm{SB}=$ soma das bases; $\mathrm{CTC}_{\text {efe }}=$ capacidade de troca de cátions efetiva; $\mathrm{CTC}_{\mathrm{pH}} 7,0=$ capacidade de troca de cátions a pH 7,0; $\mathrm{V}=$ saturação por bases; $\mathrm{m}=$ saturação por alumínio.

Os baixos teores observados para todos os metais nesse estudo, provavelmente, estão relacionados aos baixos teores de argila do solo da área em estudo e ao material de origem do mesmo, haja vista a ocorrência de ortoquarzíticos ou quartzarenitos, pobres em elementos traço. Parecem indicar também que os RSU dispostos nesse local apresentam baixas concentrações desses elementos. Esses resultados diferem de outros relatos de estudos em área de deposição de RSU, como

Tabela 2 - Teores médios As, $\mathrm{Cd}, \mathrm{Cr}$, Ni e Pb nas profundidades de 0-0,2 e 0,20-0,4 m na Área Natural, Ativa e Inativa do Lixão de Cáceres, estado de Mato Grosso.

\begin{tabular}{lcccccc}
\hline \multirow{2}{*}{ Área } & Profundidade & $\mathrm{As}$ & $\mathrm{Cd}$ & $\mathrm{Cr}$ & $\mathrm{Ni}$ & $\mathrm{Pb}$ \\
\cline { 2 - 7 } & $(\mathrm{m})$ & \multicolumn{5}{c}{$\mathrm{mg} \mathrm{kg}^{-1}$} \\
\hline \multirow{2}{*}{ Natural } & 0,20 & 0,07 & <L.D ${ }^{1}$ & 9,62 & 1,45 & 6,48 \\
\cline { 2 - 7 } & 0,40 & 0,09 & <L.D. & 11,77 & 2,31 & 7,12 \\
\hline \multirow{2}{*}{ Ativa } & 0,20 & 0,08 & <L.D. & 9,02 & 1,62 & 5,76 \\
\cline { 2 - 7 } & 0,40 & $<$ L.D. & <L.D. & 10,50 & 2,33 & 6,53 \\
\hline \multirow{2}{*}{ Inativa } & 0,20 & 0,22 & <L.D. & 6,27 & 0,85 & 5,55 \\
\hline & 0,40 & 0,31 & <L.D. & 6,70 & 1,03 & 5,99 \\
\hline
\end{tabular}

${ }^{1}$ L.D. = limite de detecção do aparelho; Resultado menor que o limite de detecção do método. $\mathrm{LD}\left(\mathrm{mg} \mathrm{L}^{-1}\right)=$ As 0,015 ; Cd 0,001; $\mathrm{Pb} \mathrm{0,005;} \mathrm{Cr} \mathrm{0,001e} \mathrm{Ni} \mathrm{0,002.}$ por exemplo, os estudos de Sisinno \& Moreira (1996), os quais verificaram teores elevados de $\mathrm{Pb}$ na área do aterro sanitário da cidade de Niterói-RJ; Muñoz (2002) encontrou altas concentrações de metais pesados nas amostras de solo e vegetais da área do aterro Sanitário de Ribeirão Preto - SP; e Melo et al. (2001) encontraram no solo da área onde foi realizada a disposição de resíduos sólidos urbanos de Passo Fundo - RS por cerca de 8 décadas de uso, elevados teores de $\mathrm{Hg}, \mathrm{Zn}$, $\mathrm{Cu}, \mathrm{Fe}, \mathrm{Cr}, \mathrm{Ni}$ e Mn. Santana et al. (2008) verificaram alteração na concentração de metais pesados, tanto no solo, quanto no tecido foliar das espécies amostradas em áreas adjacentes a um aterro em Brasília-DF, quando comparada ao solo e plantas coletadas na área-controle e nos valores de referência da literatura. Santana \& Barroncas (2007) também verificaram, em uma bacia hidrográfica na Amazônia, altos teores de metais pesados $(\mathrm{Zn}, \mathrm{Co}, \mathrm{Ni}, \mathrm{Cu}, \mathrm{Fe}$, e $\mathrm{Pb})$ conforme o que é estabelecido pelo CONAMA (resolução 357/2005) e algumas agências internacionais de proteção ambiental de alguns países.

Os teores de matéria orgânica (Tab. 1) na área natural foram maiores em relação às demais áreas $(\mathrm{p}=$ $0,0002587)$. Essa área apresenta cobertura vegetal nativa, fator que contribui para preservação dos teores de matéria orgânica no solo. Apesar da deposição de lixo na área ativa, inclusive com uma média de 24 t/dia de lixo orgânico (Alcântara \& Pierangeli 2010), a movimentação e o revolvimento do solo para escavação e aterramento provavelmente está reduzindo a proteção física da 
matéria orgânica do solo (Oliveira \& Jucá 2004), bem como favorecendo a sua decomposição.

A capacidade de troca de cátions (CTC) é um atributo que interfere na mobilidade dos metais (Zanchetta 2007), pois quanto maior a CTC maior a quantidades de sítios disponíveis para a retenção dos metais catiônicos. As amostras analisadas apresentaram $\mathrm{CTC}_{\mathrm{pH} 7}$ média, na faixa de 6,96 a 7,52 $\mathrm{cmol}_{\mathrm{c}} \mathrm{dm}^{-3}$ (Tab. 1), enquanto a CTC foi baixa, com valores na faixa de 1,39 a 2,15 $\mathrm{cmol}_{\mathrm{c}}$ $\mathrm{dm}^{-3}$, sendo superior na Área Natural. Esse fato se deve, provavelmente, à maior quantidade de matéria orgânica nessa área (Tab. 1). Em solos tropicais e subtropicais a matéria orgânica é a principal fornecedora de cargas negativas para o solo, com grande importância na retenção de cátions (Mendonça \& Silva 2007). Esses autores ressaltaram, ainda, que a degradação da matéria orgânica, em condições inadequadas de manejo é rápida e vem acompanhada de processo de degradação de importantes características químicas físicas e biológicas do solo.

Os valores médios do $\mathrm{pH}$ nas áreas variaram entre 5,3 e 5,7. Nesse sentido, Kabata Pendias \& Pendias (2001) relatam que o $\mathrm{Cr}$ em valor de $\mathrm{pH} 5,5$, se encontra praticamente todo precipitado, sendo seus compostos considerados muito estáveis no solo. Por outro lado, o $\mathrm{Cr}^{6+}$ é muito instável em solos e é facilmente mobilizado em meio ácido ou alcalino. Enquanto a adsorção do $\mathrm{Cr}^{6+}$ diminui com o aumento do $\mathrm{pH}$, a adsorção do $\mathrm{Cr}^{3+}$ aumenta (Guilherme et al. 2005). Neste estudo, observou-se uma correlação positiva $(\mathrm{P}=0,03095 ; \mathrm{r}=0,58)$ entre os teores de $\mathrm{Cr}$ e o $\mathrm{pH}$ do solo.

A saturação por bases foi muito baixa em todas as áreas, conforme critérios de Alvarez et al. (1999), evidenciando pobreza do material de origem em cátions básicos ou intensa lixiviação de bases. Em decorrência disso a saturação por cátions ácidos foi elevada (> $80 \%$ ) nas três áreas, refletindo na acidez potencial $(\mathrm{H}+\mathrm{Al})$, a qual foi alta em todas as áreas, sendo maior na área inativa
(AI). A baixa fertilidade do solo verificada na área do Lixão pode dificultar o estabelecimento de vegetação nessa área, expondo o solo aos agentes erosivos e facilitando o carreamento de materiais mais finos (por exemplo, argila e silte e material orgânico) para corpos hídricos que deságuam no Pantanal Matogrossense.

Apesar do Lixão de Cáceres-MT receber uma grande quantidade diária de lixo ( 40 t), não foi verificado contaminação do solo por elementos traço. Todavia, na ocasião das amostragens e no local de disposição final, verificou-se a presença de todos os tipos de resíduos que potencialmente agregam esses elementos em sua composição. Mesmo sendo depositado em pequenas quantidades, isso pode se tornar um agravante a longo prazo, tendo em vista a característica não biodegradável e acumulativa desses elementos.

A recuperação de áreas degradadas por disposição de lixo é uma atividade que tem sido cada vez mais empregada no Brasil, apesar de pouco discutida. É notória a necessidade de intervir na área do lixão de Cáceres - MT, com o intuito de encerrar a sua operação, requalificando-o ambientalmente ao espaço onde está inserido, reduzindo os impactos ambientais negativos sofridos pela área $\mathrm{e}$ dando-lhe outra finalidade. Nesse sentido recomenda-se um Plano de Gestão Ambiental para o local, num âmbito multidisciplinar, que vise a recuperação do mesmo, promovendo a reinserção dessa área recuperada na vida social da comunidade.

CONCLUSÕES Verificou-se que os teores de elementos traço no solo do lixão de Cáceres - MT estão abaixo dos limites de referência estabelecidos para solos do estado de São Paulo.

A natureza arenosa dos solos da área do lixão possibilita baixa capacidade de retenção dos metais catiônicos, tornando-a inadequada para depósitos de resíduos sólidos urbanos.

\section{Referências}

Abreu C.A., Abreu M.F. Berton R.S. 2002. Análise química de solo para metais pesados. In: Alvarez V.V.C.H., Schaefer C.E.G.R., Barros N.F., Mello J.W.V., Costa L.M. (eds.) Tópicos em Ciência do Solo. Viçosa, Sociedade Brasileira de Ciência do Solo, p. 645-692.

Accioly A.M.A \& Siqueira J.O. 2000. Contaminação Química e Biorremediação do Solo. In: Novais R.F., Alvarez V.V.C.H., Schaefer C.E.G.R. (eds.) Tópicos em Ciência do Solo, Viçosa, Sociedade Brasileira de Ciência do Solo, p. 300-307.

Alcântara A.J.O. \& Pierangeli M.A.P. 2010. Composição gravimétrica dos resíduos sólidos urbanos e caracterização química do solo da área de disposição final do município de Cáceres-MT. In: Santos J.E, Galbiati C., Moschini L.E. (eds.) Gestão e Educação Ambiental: água, biodiversidade e cultura. São Carlos, Editora Rima, p. 1-30.

Almeida F.F.M. 1964. Geologia do Centro-Oeste matogrossense. Boletim da Divisão de Geologia e Mineralogia, 215:1-133.
Alvarez V.V.H., Novais R.F. de, Barros N.F., Cantarutti R.B., Lopes A.S. 1999. Interpretação dos resultados das análises de solos. In: Ribeiro A.C., Guimarães P.T.G., Alvarez V.H. (eds.) Recomendações para o uso de corretivos e fertilizantes em Minas Gerais. Viçosa, Sociedade Brasileira de Ciência do Solo, p. 25-32.

Andrade F.V. 2009. Metais pesados em solos de área de mineração e metalurgia de chumbo. II - formas e Disponibilidade para plantas. Revista Brasileira Ciência do Solo, 33:1889-1897.

Beck M.H. 2005. Investigação de área degradada pela disposição de resíduos sólidos urbanos no município de Passo Fundo. Dissertação de Mestrado, Faculdade de Engenharia e Arquitetura, Universidade de Passo Fundo, Passo Fundo, 89 p.

Casarini D.C.P. \& Lemos M.M.G. 2001. Relatório de estabelecimento de valores orientadores para os solos e águas subterrâneas no estado de São Paulo. São Paulo, CETESB, 73 p. 
Castilhos Jr. A.B. (coord.). 2003. Resíduos sólidos urbanos: aterro sustentável para municípios de pequeno porte. Rio de Janeiro, ABES/RIMA, 294 p.

Celere M.S., Oliveira A.S., Trevilato T.M.B., Muñoz S.I.S. 2007. Metais presentes no chorume coletado no aterro sanitário de Ribeirão Preto, São Paulo, Brasil, e sua relevância para saúde pública. Cadernos de Saúde Pública, 23(4):939-947.

CETESB - Companhia de Tecnologia de Saneamento Ambiental. 2005. Decisão da Diretoria $n^{\circ}$ 195/2005. Valores orientadores para solos e águas subterrâneas do estado de São Paulo. Disponível em: http://www. cetesb.sp.gov.br/Solo/relatorios/tabela_valores_2005. pdf. Acessado em: 23/07/2009.

Chagas W. 2000. Estudo de patógenos e metais em lodo digerido bruto e higienizado para fins agrícolas, das estações de tratamento de esgotos da Ilha do Governador e da Penha no estado do Rio de Janeiro. Dissertação de Mestrado, Escola Nacional de Saúde Pública, Fundação Oswaldo Cruz, Rio de Janeiro, $142 \mathrm{p}$.

Damasceno S. 1996. Remoção de metais pesados em sistemas de tratamento de esgoto sanitário por processo de lodo ativado e por um reator compartimentado anaeróbio. Dissertação de Mestrado, Escola de Engenharia de São Carlos, Universidade de São Paulo, Sã Carlos, 141 p.

Duffus J.H. 2001. "Heavy metals" - a meaningless term? Pure Applied Chemistry, 74(5):793-807.

EMBRAPA - Empresa Brasileira de Pesquisa Agropecuária. 1997. Manual de Métodos de Analises de Solo. 2.ed., Brasília, Embrapa, 212 p.

EMBRAPA - Empresa Brasileira de Pesquisa Agropecuária. 2006. Sistema brasileiro de classificação de solos. 2.ed., Brasília, Embrapa, 306 p.

Fadigas F.S., Sobrinho N.M.B.A., Mazur N., Anjos L.H.C., Freixo A.A. 2002. Concentrações naturais de metais pesados em algumas classes de solos brasileiros. Bragantia, 61(2):151-159.

Guilherme L.R.G., Marques J.J., Pierangeli M.A.P., Queiróz Z., Campos M.L., Marchi G. 2005. Elementos-traço em solos e sistemas aquáticos. Tópicos em Ciência do Solo, 4:345-390.

IBGE - Instituto Brasileiro de Geografia e Estatística. 2002. Pesquisa Nacional de Saneamento Básico. Rio de Janeiro, IBGE, Relatório Técnico, 397 p.

Kabata-Pendias A. \& Pendias H. 2001. Trace elements in soil and plants. 3.ed. Boca Raton, CRC Press, 413 p.

Korf E.P., Melo E.F.R.Q., Thomé A., Escosteguy P.A.V. 2008. Retenção de metais em solo da antiga área de disposição de resíduos sólidos urbanos de Passo FundoRS. Revista de Ciências Ambientais, 2(2):43-60.

Ladeira A.C.Q., Ciminelli V.S., Nepomuceno A.L. 2002. Seleção de solos para a imobilização de arsênio. Revista Escola de Minas, 55(3):215-221.

Lange L.C., Simões G.F., Ferreira C.F.A., Coelho H.M.G. 2002. Estudo do transporte de contaminantes em meios porosos aplicado a aterros de disposição de resíduos sólidos urbanos. In: Castilhos Jr. A.B. de, Lange C.L., Gomes L.P., Pessin N. (orgs.) Alternativas para disposição de resíduos sólidos urbanos para pequenas comunidades: coletânea de trabalhos técnicos. Rio de Janeiro, ABES/ RIMA, p. 85-92.

Lauermann A. 2007. Caracterização química dos efluentes gerados pelo aterro controlado de Santa Maria e retenção de chumbo e zinco por um argissolo da depressão central do Rio Grande do Sul. Dissertação de Mestrado, Centro de Ciências Rurais, Universidade Federal de Santa Maria, Santa Maria, 72 p.

Luz J.S. 1978. Projeto Província Serrana. Goiânia, DNPM/ CPRM, Relatório Final, 105 p.

Mavropoulos E. 1999. A hidroxiapatita como absorvedor de metais. Dissertação de Mestrado, Escola Nacional de Saúde Pública, Fundação Oswaldo Cruz, Rio de Janeiro, $126 \mathrm{p}$.

Melo E.F.R.Q., Coronetti L., Garbin C., Fiori A., Thomé A., Scheneider I.A.H. 2001. Contaminação provocada por resíduos sólidos urbanos na área do aterro invernadinha - Passo Fundo, RS. Bragantia, 51:141-148.

Mendonça E.S. \& Silva I.R. 2007. Matéria orgânica do solo. In: Novais R.F., Alvarez V.V.H., Barros N.F., Fontes R.L.F., Cantarutti R.B., Neves J.C.L. (eds.) Fertilidade do solo. Viçosa, Sociedade Brasileira de Ciência do Solo, p. 275-374.

Mucelin C.A. \& Bellini M. 2008. Lixo e impactos ambientais perceptíveis no ambiente urbano. Revista Sociedade \& Natureza, 20:111-124.

Muñoz S.I.S. Impacto ambiental na área do aterro sanitário e incinerador de resíduos sólidos de Ribeirão Preto-SP: avaliação dos níveis de metais pesados. 2002. Tese de Doutorado, Escola de Enfermagem de Ribeirão Preto, Universidade de São Paulo, Ribeirão Preto, 159 f.

Oliveira F.J.S. \& Jucá J.F.T. 2004. Acúmulo de metais pesados e capacidade de impermeabilização do solo imediatamente abaixo de uma célula de um aterro de resíduos sólidos. Revista de Engenharia Sanitária e Ambiental, 9(3):211-217.

Oliveira S. 2001. Avaliação da qualidade da água subterrânea a jusante do depósito de resíduos sólidos municipais de Botucatu/SP. 2001. Tese de Doutorado, Faculdade de Ciências Agronômicas, Universidade Estadual Paulista Júlio de Mesquita Filho, Botucatu, 232 p.

Paye H.S., Mello J.W.V de, Abrahão W.A.P., Fernandes Filho E.I., Dias L.C.P., Castro M.L.O., Melo S.B., França M.M. 2010. Valores de referência de qualidade para metais pesados em solos no estado do Espirito Santo. R. Bras. Ci. Solo, 34:2041-2051.

Pierangeli M.A.P., Guilherme L.R.G., Oliveira L.R., Curi N., Silva M.L.N. 2001. Efeito da força iônica da solução de equilíbrio sobre a adsorção/dessorção de chumbo em Latossolos brasileiros. Revista Pesquisa Agropecuária Brasileira, 36(8):1077-1084.

Pierangeli M.A.P., Guilherme L.R.G., Oliveira L.R., Curi N., Silva M.L.N. 2003. Efeito da força iônica da solução de equilíbrio na adsorção de cádmio em Latossolos brasileiros. Pesquisa Agropecuária Brasileira, 38(2):737-745.

Pierangeli M.A.P., Eguchi E., Ruppin R.F., Costa R.B.F., Vieira D.F. 2009. Teores de As, $\mathrm{Pb}, \mathrm{Cd}$ e $\mathrm{Hg}$ e fertilidade de solos da região do Vale do Alto Guaporé, sudoeste do estado de Mato Grosso. Revista Acta Amazônica, 39(1):61-70. 
RADAMBRASIL. 1982. Levantamento dos recursos naturais. Cuiabá - Rio de Janeiro. Folha SD 21. Rio de Janeiro, DNPM, Projeto RADAMBRASIL, 448 p.

Ribeiro A.C., Guimarães P.T.G., Alvarez V.H. 1999. Recomendações para ouso de corretivos e fertilizantes em Minas Gerais. Viçosa, Sociedade Brasileira de Ciência do Solo, 359 p.

Rocca A.C.C., Iacovone A.M.M.B., Barrotti A.J., Casarini D.C.P., Gloeden E., Straus E.L., Romano J.A., Ruiz L.R., Silva L.M., Saito L.M., Pires M.C., Leão M.L.G., Neto P.P.C., Collucci R., Cunha R.C.A. 1993. Resíduos sólidos industriais. 2.ed. São Paulo, CETESB, 234 p.

Rosolen V., Herpin U., Coelho N.M.M., Coelho L.M., Brito J.L.S., Silva L.A. da, Carmo S. do. 2009. Qualidade dos sedimentos no rio Uberabinha (Uberlândia, MG) e implicações ambientais. Revista Brasileira de Geociências, 39(1):151-159.

Ross J.L.S. 1987. Estudo e cartografia geomorfologica da provincia serrana - MT. Tese de Doutorado, Faculdade de Filosofia, Letras e Ciências Humanas, Universidade de São Paulo, São Paulo, 326 p.

Sakuma A.M., Capitani E.M., Tiglea P. 2003. Arsênio. In: Azevedo F.A. \& Chasin A.A.M. (eds.) Metais: gerenciamento da toxicidade. São Paulo, Atheneu, p. 203-238.

Santana G.P. \& Barroncas P. de S. 2007. Estudo de metais pesados (Co, $\mathrm{Cu}, \mathrm{Fe}, \mathrm{Cr}, \mathrm{Ni}, \mathrm{Mn}, \mathrm{Pb}$ e $\mathrm{Zn}$ ) na Bacia do Tarumã-Açu Manaus - (AM). Acta Amazônica, 37(1):111-118.

Santana O.A., Encinas J.I., Correa R.S., Junior A.F.C. 2008. Nutrientes e metais no solo e em árvores de cerrado adjacentes a um aterro sanitário. Revista Cerne, 14(3):212-219.

Santos H.G., Jacomine P.K.T., Anjos L.H.C., Oliveira V.A., Oliveira J.B., Coelho M.R., Lumbrelas J.F., Cunha T.J.F. 2006. Sistema brasileiro de classificação dos solos. 2.ed. Brasília, Embrapa, 306 p.
Santos P.C.V. 1996. Estudo da contaminação de água subterrânea por percolado de aterro de resíduos sólidos - Caso Jockey Club - DF. Dissertação de Mestrado, Faculdade de Tecnologia, Universidade de Brasília, Brasília, 135 p.

Santos R.D., Lemos R.C., Santos H.G., Anjos L.H.C. 2005. Manual de descrição e coleta de solo no campo. 5.ed., Viçosa, Sociedade Brasileira de Ciência de Solo, 100 p.

Sisinno C.L.S. \& Moreira J.C. 1996. Avaliação da contaminação e poluição ambiental na área de influência do aterro controlado do Morro do Céu, Niterói, Brasil. Cadernos de Saúde Pública, 12(4):515-523.

Souza C.A. 1998. Bacia hidrográfica do córrego Piraputanga (MT): avaliação da dinâmica atual. Dissertação de Mestrado, Instituto de Geociências, Universidade Federal do Rio de Janeiro, Rio de Janeiro, $117 \mathrm{p}$.

Souza C.A, Souza J.B., Silva L.N.P., Pierangeli M.A.P. 2010. Caracterização ambiental da bacia hidrográfica do córrego Piraputangas (Rio Paraguai). In: Santos J.E., Galbiati C., Moschini L.E. (eds.) Gestão e Educação Ambiental: água, biodiversidade e cultura. São Carlos, Editora Rima, p. 1-30.

Susuki E.Y., Taioli F., Rodrigues C.L. 2005. Avaliação do comportamento geoquímico do solo da região do lixão de Ilha Bela-SP. Revista Águas Subterrâneas, 19(2):67-76.

Zanchetta G.S.B. 2007. Avaliação do grau de poluição do solo, águas, plantas e resíduos sólidos do lixão Linha Rincão do Engenho de Lagoa Vermelha-RS. Dissertação de Mestrado, Faculdade de Engenharia e Arquitetura, Universidade de Passo Fundo, Passo Fundo, 149 p.

Manuscrito ID 20749 Aceito em 13 de outubro de 2011 